\title{
Compromisso constitucional da sustentabilidade ambiental: desafios de sua concretização frente à necessidade de revisão do ensino jurídico e atualização dos implementadores judiciais da normatividade ambiental
}

\begin{abstract}
Constitutional commitment of the environmental sustainability: challenges to its achievement due to the need for review of legal education and update of judicial implementers of environmental normativity
\end{abstract}

Norma Sueli Padilha*

\section{Resumo}

Os valores primordiais da sociedade brasileira estão inseridos na Carta Magna por meio de princípios, que enquanto normas jurídicas constitucionais representam a reintegração dos valores morais e éticos no universo jurídico na era do pós-positivismo. Dentre os valores albergados pela CF/88, destaque-se o "meio ambiente ecologicamente equilibrado", alçado ineditamente no nível de direito fundamental e inaugurando um novo paradigma ético-jurídico e políticoeconômico que opta pelo desenvolvimento sustentável. A concretização de tal compromisso constitucional impõe inúmeros desafios àqueles a quem cabe o dever de implementação da juridicidade ambiental constitucional, dada a gravidade e a complexidade das demandas socioambientais, cuja tutela judicial exige transformações substanciais nos instrumentos jurídicos tradicionais de direito material e processual, bem como atualização e revisão de conceitos e institutos de natureza individualista, que, entretanto, ainda são o objeto central

Pós-doutoranda pela UNICAMP, Doutora em Direito Difusos e Coletivos pela PUC/SP, Professora do Programa de Mestrado em Direito da Universidade Católica de Santos - UNISANTOS, Professora Adjunta da Universidade Federal do Mato Grosso do Sul UFMS. E-mail: normasp@uol.com.br 
do modelo positivista que é ministrado na formação dos bacharéis nos Cursos Jurídicos do Brasil.

Palavras-chave: Direito fundamental ao meio ambiente. Sustentabilidade ambiental. Lides ambientais. Tutela judicial do meio ambiente. Ensino jurídico.

\section{Abstract}

The major values of Brazilian society are included in the Constitution through principles, which as constitutional rules of law represent the reinstatement of moral and ethical values in the legal universe of the post-positivism era. Among the values included in the Constitution the "ecologically balanced environment", unprecedentedly raised to the condition of fundamental right, opened a new ethical-legal and political-economic paradigm that chooses for sustainable development. The achievement of such constitutional commitment requires numerous challenges to those entrusted with the duty of implementing the constitutional legality environmental, due to the seriousness and complexity of socio-environmental demands, whose judicial protection requires substantial changes in the traditional legal instruments of substantive and procedural law as well as the update and revision of concepts and institutions of an individualistic nature, which, however, are still the main object of the positivist model that is taught in the training of graduates in Legal Courses in Brazil.

Keywords: Fundamental right to the environment. Environmental sustainability. Environmental litigation. Judicial protection of the environment. Legal education.

\section{Introdução}

Aconsiderável extensão física do território brasileiro e a diversidade de riquezas naturais nele existente tornam o Brasil um ator internacional relevante nas questões ambientais mundiais. As consequências de sua atuação ou omissão no desempenho de sua responsabilidade em relação a tamanho patrimônio natural podem, inclusive, afetar o equilíbrio ambiental global, uma vez que, no território brasileiro, se encontra cerca de $15 \%$ a $20 \%$ da biodiversidade das espécies vegetais e animais do mundo. 
Considerado um dos países com maior abundância e variedade de espécies de plantas e flores do planeta, o território brasileiro é um tesouro a céu aberto, quando o assunto é biodiversidade. O território brasileiro abriga biomas riquíssimos em patrimônio natural, tais como: a Mata Atlântica, o Pantanal, o Cerrado, a Caatinga, bem como a maior floresta tropical do Planeta, a Floresta Amazônica, entretanto, apesar de tamanha riqueza de patrimônio natural, o Brasil possui pouquíssimo conhecimento sobre a biodiversidade que compõe tais ecossistemas, além de não investir em políticas públicas de proteção efetiva. Por falta de gestão administrativa adequada e planejamento integrado de ações entre os entes da Federação (União, Estados e Municípios), a biodiversidade brasileira fica submetida a uma cultura social de desrespeito e descuido, a um mercado econômico de exploração irracional e agressiva, sendo vítima fácil da cobiça, nacional e internacional, como mera fornecedora de matérias primas para o mercado de consumo.

Desta forma, não há dúvida de que o marco regulatório e a qualidade da proteção jurídica do meio ambiente, em toda sua abrangência que, além do meio ambiente natural (elementos bióticos e abióticos) alcança também o meio ambiente artificial (urbano, cultural e do trabalho), é de suma importância em um País de dimensões continentais como o Brasil, depositário de uma considerável parcela do patrimônio natural do Planeta e em pleno desenvolvimento econômico e social. ${ }^{1}$ Entretanto, a cultura do desenvolvimento irracional e insustentável prevalece no País, vitimando os mais pobres e o meio ambiente; assim, expressivos são os conflitos que envolvem a colisão de interesses em confronto com o equilíbrio do meio ambiente, gerando lides socioambientais que necessitam de solução urgente e adequada.

Portanto, é de crucial importância não só a qualidade do tratamento jurídico dado ao tema da questão ambiental no contexto nacional, mas

Registre-se que na Conferência das Nações Unidas sobre Meio Ambiente e Desenvolvimento (CNUCED), o Brasil foi considerado como um dos poucos países detentores de megadiversidade. 
sua implementação, pois sua real concretização está diretamente relacionada à sadia qualidade de vida de toda a sociedade brasileira, e não só das presentes, mas também das futuras gerações.

Quanto à qualidade do marco regulatório ambiental, a constitucionalização da proteção ambiental adotada pela Constituição brasileira de 1988 é inovadora e pioneira, alçando a proteção do meio ambiente ecologicamente equilibrado, na condição de um valor essencial à sadia qualidade de vida de todos, adotado na qualidade de direito fundamental, por meio de um capítulo específico, em plena consonância com as Constituições democráticas pioneiras na proteção constitucional do meio ambiente. ${ }^{2}$

Aadoção constitucional de proteção do equilíbrio do meio ambiente sugere um novo paradigma ético-jurídico e político-econômico, referido a uma sociedade que assumiu o compromisso de um desenvolvimento que respeite o meio ambiente e o proteja com especial prioridade.

Entretanto, a implementação do equilíbrio do meio ambiente enfrenta inúmeros e grandiosos desafios, pois está no centro de colisão de grandes conflitos de interesses da sociedade brasileira, gerando complexas lides socioambientais que exigem dos implementadores da normatividade ambiental uma atuação eficaz e inovadora, sob pena de comprometer-se a promessa de sustentabilidade ambiental do texto constitucional.

Nesse contexto, é que o presente artigo objetiva apresentar uma reflexão sobre a interligação entre a possibilidade de efetividade do modelo de sustentabilidade ambiental adotado constitucionalmente, com a necessária mudança de postura dos implementadores judiciais da normatividade ambiental, por meio da assimilação dos novos contornos jurídicos da proteção do equilíbrio do meio ambiente. A reflexão destaca

2 Conforme art. 225 que inaugura um capítulo específico para o meio ambiente no texto constitucional: "Todos tem direito ao meio ambiente ecologicamente equilibrado, bem de uso comum do povo e essencial à sadia qualidade de vida, impondo-se ao Poder Público e a coletividade o dever de defendê-lo e preservá-lo para as presentes e futuras gerações." 
a importância do adequado conhecimento científico do Direito Ambiental, enquanto disciplina jurídica autônoma, com princípios próprios e diferenciados, de caráter multidisciplinar e alcance transversal em todas as demais áreas do Direito, por meio de sua inclusão obrigatória no Ensino Jurídico, pois o conhecimento abrangente da normatividade ambiental e suas especificidades e objetivos estão diretamente relacionadas à adequada capacitação dos implementadores judiciais do paradigma ambiental.

É de suma importância para os desafios de efetividade da proteção constitucional do meio ambiente uma profunda reflexão sobre todas as medidas e mecanismos que possam garantir uma atuação mais eficiente do Poder Judiciário frente às complexas lides socioambientais.

\section{A proteção do meio ambiente: um valor essencial elevado à categoria de norma constitucional de direito fundamental}

A constitucionalização da proteção jurídica do meio ambiente, na qualidade de um valor essencial da sociedade brasileira, alçado a nível constitucional pela Constituição brasileira de 1988, de forma pioneira dentre as nações democráticas, na condição de direito ao "meio ambiente ecologicamente equilibrado", bem essencial à sadia qualidade de vida de todos, enquanto um direito fundamental de terceira dimensão impõe uma nova abordagem da tutela jurídica do meio ambiente, pois adota uma visão holística e sistêmica, norteadora de diversas alterações no ordenamento jurídico clássico.

É importante ressaltar que a Constituição Federal de 1988 representa para o ordenamento jurídico brasileiro o atual estágio do constitucionalismo moderno onde é nítida a reaproximação entre Ética e Direito, exatamente pela incorporação no texto constitucional dos "valores comunitários primordiais", que passam a estar abrigados na Constituição em forma de princípios explícitos ou implícitos. E, conforme ensina Luiz Roberto Barroso (2001, p. 43), 
os princípios passam a ser síntese dos valores abrigados no ordenamento jurídico. Eles espelham a ideologia da sociedade, seus postulados básicos, seus fins. Os princípios dão unidade e harmonia ao sistema, integrando suas diferentes partes e atenuando tensões normativas.

Não se discute que os princípios jurídicos sempre desempenharam papel importante na ordem jurídica, pois dão unidade e harmonia ao sistema, servindo de guia para o intérprete, mas a diferença no constitucionalismo moderno e na nova hermenêutica constitucional é o reconhecimento de sua plena normatividade pela conquista do status de norma jurídica.

De acordo com Luís Roberto Barroso (2001, p.48-58), "o Direito é um sistema aberto de valores. A Constituição, por sua vez, é um conjunto de princípios e regras destinados a realizá-los, a despeito de se reconhecer nos valores uma dimensão suprapositiva"; desta forma, supera-se o puro legalismo do positivismo normativista, pelo "reconhecimento da normatividade dos princípios e a essencialidade dos direitos fundamentais".

Portanto, os princípios devem ser reconhecidos não mais como meras exortações, como meros preceitos de ordem moral ou política, mas como normas, com todo o seu conteúdo de juridicidade e imperatividade.

Como bem assevera Paulo Bonavides (1999, p. 259), a distinção a ser feita não é entre princípios e normas, pois as normas compreendem, como suas espécies, os princípios e as regras; logo, a distinção relevante é entre princípios e regras, destacando a "superioridade e hegemonia dos princípios na pirâmide normativa", numa supremacia não unicamente formal, mas material, uma vez que os princípios são equiparados com os "valores", portanto, "sendo na ordem constitucional dos ordenamentos jurídicos, a expressão mais alta da normatividade que fundamenta a organização do poder".

Destaque-se que os princípios são diretrizes centrais de um sistema jurídico que lhe conferem uma compreensão sistêmica, além de 
ser essencial apoio para a integração e interpretação da ordem jurídica. Segundo Bonavides (1999, p. 254), são "a pedra de toque ou o critério com que se aferem os conteúdos constitucionais em sua dimensão normativa mais elevada", destacando três funções primordiais: a função de ser fundamento da ordem jurídica, com eficácia derrogatória e diretiva (conforme o Direito Constitucional contemporâneo); a função orientadora do trabalho interpretativo e a de fonte em caso de insuficiência da lei e do costume (funções mais tradicionais). Segundo Ingo Wolfgang Sarlet (2005, p. 111), a Constituição de 1988

deixa transparecer de forma clara e inequívoca a sua intenção de outorgar aos princípios fundamentais a qualidade de normas embasadoras e informativas de toda a ordem constitucional, inclusive dos direitos fundamentais, que integram aquilo que se pode denominar de núcleo essencial da Constituição material.

Desta forma, o constitucionalismo moderno adota a técnica de abrigar os valores primordiais da sociedade no texto constitucional, pela via dos princípios constitucionais e dos direitos fundamentais e é neste contexto que o direito ao equilíbrio do meio ambiente se insere.

Assim, o direito ao meio ambiente ecologicamente equilibrado foi erigido pela Constituição Federal de 1988, como bem essencial à sadia qualidade de vida, garantido como um direito fundamental, por meio de uma normatividade extremamente instigante e abrangente, que quebra, inclusive, o paradigma da normatividade tradicional do ordenamento jurídico pátrio. É um direito que traduz, pela primeira vez, um compromisso intergeracional, um pacto da atual geração com a geração futura, no sentido de respeito e preservação do equilíbrio ambiental como um bem comum.

Por outro lado, na qualidade de um direito fundamental, o meio ambiente está abrigado pela Constituição Federal de 1988 por um especial reforço e status jurídico, pois o texto constitucional determina que as normas definidoras de direitos e garantias fundamentais possuem aplicabilidade imediata, nos termos do art. $5^{\circ}, \S 1^{\circ}$, vinculando de forma 
imediata as entidades públicas e privadas, além de estarem incluídas, ainda, dentre o rol das "cláusulas pétreas" do art. $60, \S 4^{\circ}$, o que impede sua supressão pelo Poder Constituinte derivado e as coloca no topo do ordenamento jurídico constitucional.

Nesse sentido, o direito fundamental ao meio ambiente não admite "retrocesso ecológico", possuindo uma função limitativa do poder e norteando os próprios fins do Estado constitucional moderno, consubstanciando em uma ordem dirigida a todos os entes da Federação e órgãos do Estado, no exercício das suas competências e atribuições específicas, quer na área legislativa ou administrativa, da obrigação e do dever de concretizar e realizar a norma ambiental constitucional, pois nenhum agente público ou privado, pode tratar o meio ambiente como valor acessório ou de menor importância.

O direito ao meio ambiente é um direito fundamental de terceira dimensão, enquanto um direito cujo destinatário é o conjunto de toda a humanidade, um direito voltado à solidariedade, como a paz, a autoderminação dos povos, o desenvolvimento. Os direitos fundamentais de terceira dimensão são direitos gerados na sociedade de massa, resultantes dos inúmeros fatores da modernidade, tais como os impactos do avanço tecnológico, do crescimento desordenado, da degradação ambiental, do crescimento populacional, da globalização econômica, dentre outros. Conflitos sociais que se massificaram, gerando novas demandas de direitos fundamentais, que, na perspectiva da terceira dimensão, trazem a nota distintiva da titularidade coletiva, indefinida e indeterminável, e do objeto indivisível, bem como, da alta complexidade, tal qual o meio ambiente e a qualidade de vida.

Por sua vez, o direito fundamental ambiental é alicerçado constitucionalmente sobre novos pilares que implicam mecanismos de políticas públicas, gestão solidária e responsabilidade compartilhada, tudo em prol de sua efetiva concretização, pois, conforme bem acentua José Joaquim Gomes Canotilho (2007, p. 5):

[...] a força normativa da Constituição ambiental dependerá da concretização do programa jurídico-constitucional, pois 
qualquer Constituição do ambiente só poderá lograr força normativa se os vários agentes - públicos e privados - que actuem sobre o ambiente o colocarem como fim e medida das suas decisões.

Em decorrência da constitucionalização da defesa do meio ambiente, refere-se Antonio Herman Benjamin (2007, p.65) à "ecologização do texto constitucional" (CANOTILHO, 2007, p.58), e à adoção de um novo paradigma ético-jurídico, político-econômico, em que o "eu individualista é substituído pelo nós coletivista", uma vez que, ao reconhecer o direito ao meio ambiente, a CF/88 adota uma nova ordem pública, "centrada na valorização da responsabilidade de todos para com as verdadeiras bases da vida, a Terra". Denuncia que o paradigma constitucional anterior possuía uma visão fragmentada, de mera exploração de recursos ambientais, e o paradigma atual atende uma visão sistêmica e holística do meio ambiente, contendo um compromisso ético para com as futuras gerações de não esgotamento dos recursos naturais, além de uma atualização do direito de propriedade que contém uma nova dominialidade de certos recursos ambientais e o comprometimento com a função social.

É interessante notar que a atual abordagem do texto constitucional brasileiro, dada à questão ambiental, não foi fruto de amadurecimento da construção teórica do Direito Ambiental nacional, na verdade, reflete a influência da construção normativa do Direito Internacional do Meio Ambiente. O meio ambiente logrou alçar o nível de proteção constitucional na Carta de 1988, ao mesmo tempo, em que se desenvolve a própria teoria geral do Direito Ambiental no Brasil, que muito embora tenha em poucos anos, conquistado sua autonomia como disciplina jurídica, ainda se encontra em construção e luta pela sua afirmação, diante do dinamismo das realidades ambientais e dos desafios impostos a juridicidade ambiental.

Para Antonio Herman Benjamin (2007, p.65), a teoria constitucional do meio ambiente ainda precisa ser mais profundamente explorada, pois os "fundamentos dorsais do Direito Ambiental" encontrase na Constituição, e é dela que se deve montar o "edifício teórico 
da disciplina", em busca da efetividade deste "novo paradigma éticojurídico" e "político-econômico".

Neste contexto, torna-se imperiosa a necessidade de atualização e mudança de postura de todos aqueles que atuam na seara jurídica, diante do novo paradigma da juridicidade constitucional ambiental.

O compromisso assumido pela atual Carta Constitucional com relação à questão ambiental implica uma nova abordagem jurídica da juridicidade ambiental, um novo desenho de nosso Estado Democrático de Direitos, que exige profundas reformulações sociais, econômicas e políticas de altíssima complexidade e dificuldade. Lembrando que o advento da Constituição de 1988, enquanto nossa verdadeira Constituição democrática se refere a uma expectativa não da sociedade que somos, mas da sociedade que pretendemos e queremos ser, e pela qual temos muito ainda que lutar.

Nesse sentido, pode-se afirmar que a juridicidade ambiental adotada constitucionalmente está de acordo com um modelo de "Estado constitucional ecológico" e de uma "democracia sustentada", que, conforme Canotilho (2007, p. 6), é aquele que adota a "tarefa básica do novo século: a sustentabilidade ecológico-ambiental":

O Estado de direito, hoje, só é Estado de direito se for um Estado protector do ambiente e garantidor do direito ao ambiente; Mas o Estado ambiental e ecológico só será Estado de direito se cumprir os 'deveres de juridicidade' impostos à actuação dos poderes públicos.

\section{Sustentabilidade ambiental: um novo paradigma moral e jurídico}

A proposta constitucional brasileira de elevar o direito ao meio ambiente à qualidade de direito fundamental sugere um novo paradigma: o da sustentabilidade ambiental, na medida em que adota um modelo de produção que, embora baseado na livre iniciativa, na livre concorrência e na apropriação privada de bens, estabelece como um dos seus princípios 
a defesa do meio ambiente, inclusive mediante tratamento diferenciado (art. 170, inc. VI). E, ao estabelecer a convivência da ordem econômica com a defesa e preservação do meio ambiente, por conseqüência, propôs uma juridicidade constitucional ambiental centrada na proposta de um "desenvolvimento sustentável".

Nas palavras de Canotilho (2007, p. 3-5), a sustentabilidade ecológico-ambiental é a tarefa básica do novo século; ele destacao a ecologização da ordem jurídica na Constituição ambiental como a imposição de uma "reserva constitucional do bem ambiente". Ou seja, uma ordem de não retrocesso da jusfundamentalização do ambiente imposta aos vários intérpretes da Constituição, legislador, tribunais e administração em decorrência do "princípio da proibição de retrocesso", uma vez que as políticas ambientais do Estado estão obrigadas a melhorar o nível de proteção já assegurado.

Toda a ordem jurídica ambiental anterior à nova ordem imposta pela CF/88, bem como, toda a legislação posterior, estão submetidas a determinantes, como "os princípios do desenvolvimento sustentável, do aproveitamento racional de recursos, da salvaguarda de capacidade de renovação ecológica e do princípio da solidariedade entre gerações" que impedem o retrocesso das políticas ambientais do Estado e, segundo Canotilho (2007, p. 6-8), identifica um "Estado de direito ambiental e ecológico”, o qual impõe deveres de juridicidade ambiental à atuação dos poderes públicos.

É como se, ao adotar a proteção ambiental na magnitude determinada pelo texto de 1988, o Estado de Direito Social promovesse um novo salto na sua evolução e, se transmudasse em Estado de Direito Ambiental, pelo menos na proposta abstrata e teórica do texto constitucional, mas, para tanto, inúmeras mudanças concretas precisam ser almejadas e conquistadas, nos campos social, econômico e político, para que tal proposta não soe como uma utopia, mas como uma meta a ser alcançada.

De toda forma, a Constituição impõe o dever de proteção do meio ambiente a "todos", e divide a responsabilidade de seu exercício entre 
o Estado e a sociedade, criando um elo de solidariedade, que implica inclusive um compromisso para com as futuras gerações.

A consecução de tal objetivo exige pleno exercício da cidadania participativa e dos mecanismos da democracia, e é nesse sentido que o texto constitucional impôs inúmeros instrumentos de efetivação da ordem constitucional ambiental, ampliando a participação popular, por meios administrativos e judiciais, exigindo educação ambiental, amplitude e transparência de informações e de acesso à justiça, bem como inúmeros deveres de gestão ambiental aos poderes públicos, pois a solidariedade é pressuposto para a conquista da sustentabilidade ambiental (PADILHA, 2010, p.159-160).

\subsection{Novo paradigma jurídico ambiental}

Ao adotar a proteção à preservação do meio ambiente, na qualidade de um direito fundamental, a Constituição Federal de 1988 denota claramente que o paradigma tradicional do ordenamento jurídico nacional tornou-se impotente para traduzir tão nova e complexa temática jurídica, que necessita, para sua efetiva e necessária concretização, a busca de um paradigma adequado, não mais tendo como ponto de referência a perspectiva clássica individualista.

O novo paradigma deve adequar-se à descrição mais apropriada das sociedades complexas, deve superar os limites de uma ordem jurídica que se refere apenas a conflitos bilaterais, de relações de pertença referidas à ação civil e aos fundamentos do ato e do fato jurídico. As demandas ambientais denunciam uma nova, abrangente e complexa conflituosidade, não padronizada pelo paradigma jurídico tradicional, exigindo renovação de institutos de direito material e processual e aplicação de novos instrumentos de implementação, bem como uma nova postura do Poder Judiciário.

A adoção da proteção ambiental, na qualidade de um direito constitucional, redesenha o projeto do Estado Social, que não pode ser simplesmente congelado ou interrompido: é preciso continuá-lo num nível de reflexão superior. Citando Habermas (1997, p.147-148), 
o que se tem em mente é domesticar o sistema econômico capitalista, "transformando-o", social e ecologicamente.

Trata-se de uma grande inovação no Direito Constitucional brasileiro, que abandona o tratamento jurídico do meio ambiente, por meio de legislações esparsas e sem sistematização, caracterizadas por uma conotação civilista e patrimonialista, inaugurando um novo modelo de normatividade jus ambiental, centrada na Constituição e numa abordagem nova, de proteção e responsabilização.

Refere-se a uma proposta de mudança de um velho paradigma assentado na exploração econômica e não sustentável dos recursos naturais, para um novo modelo que respeite sua função ecológica, sua importância para o equilíbrio do meio ambiente, que considere a integridade dos ecossistemas e a própria qualidade do meio ambiente e seus componentes, como bem ambiental autônomo, com valor em si e per si.

O novo paradigma constitucional ambiental desconfia das possibilidades científico-tecnológicas infinitas, pois tais possibilidades devem ser limitadas pela necessidade de preservação do equilíbrio do meio ambiente, que não continuaria a suportar, por muito mais tempo, a pressão exacerbada provocada pela degradação ilimitada. A proposta constitucional propugna uma consciência coletiva quanto à realidade de limite dos recursos naturais e do grande risco da sua exploração irracional, e alberga o compromisso da proteção do equilíbrio do meio ambiente por meio de um novo modelo de ordem jurídica ambiental, com novos comandos, novos princípios e valores, novos instrumentos, pois a dogmática tradicional não apreendia a complexidade da questão ambiental e seu necessário diálogo social e econômico (PADILHA, 2010, p. 164-165).

\subsection{Novo paradigma ético ambiental}

O imperativo da mudança de paradigma ambiental, com suas implicações na seara do jurídico, do político e do econômico, passa 
inexoravelmente pela mudança do paradigma ético ambiental. Se, ao adotar um novo compromisso constitucional referente à questão ambiental, a Constituição propõe novos modelos de juridicidade ambiental, sua efetividade depende de uma nova postura ética com reflexo em todos os setores sociais e econômicos.

A consciência de uma necessária mudança de postura de toda a sociedade na sua relação de domínio, utilização e consumo dos recursos naturais, de forma irracional, implica uma reflexão e uma busca de um novo parâmetro para o comportamento humano com relação à natureza, que substitua o quadro de desrespeito, desconsideração, descaso e descuido que tem identificado a ética tradicional predominante.

A Carta de 1988 elaborou um paradigma de constitucionalidade ambiental que pouco alcance terá na realidade efetiva, se não alicerçada em uma conscientização generalizada da sociedade como um todo, por todos os seus atores, públicos e privados, com relação à necessária mudança de postura, de tratamento e relacionamento para com o meio ambiente e seus componentes ecológicos essenciais.

É preciso que, juntamente com a nova proposta constitucional de um paradigma jus ambiental, haja também a mudança do paradigma ético ambiental. Nesse sentido, é preciso reconhecer que a Constituição Federal deu um passo importante em substituir a visão ética tradicional, alicerçada em um antropocentrismo ${ }^{3}$ exacerbado, por um "antropocentrismo mitigado" e parceiro de um saudável "biocentrismo", na medida em que, além de não desconsiderar o homem na sua relação com o seu meio ambiente, o considera nele integrado, amparando-o ao mesmo tempo em que ampara a totalidade da vida e das suas bases essenciais.

3 Lembrando que "antropocentrismo" é uma concepção que faz do Homem o centro do Universo, "a medida de todas as coisas", na famosa afirmação do filósofo grego Protágoras, o primeiro e mais famoso dos sofistas. 
Quando o artigo 225 da Constituição Federal atesta que o equilíbrio do meio ambiente é essencial à sadia qualidade de vida, está considerando o "sistema ecológico" como um ente autônomo e complexo, cujas condições e relações asseguram a vida em suas múltiplas dimensões.

Ao tutelar o direito ao "meio ambiente ecologicamente equilibrado", a CF tutela a vida em todas as suas formas, não somente a humana. $\mathrm{E}$ se o texto constitucional não chega a atribuir direitos à natureza, também não deixa de atribuir-lhe valor em si mesma, uma vez que os beneficiários do "equilíbrio ambiental" vão muito além da dimensão meramente humana. Desta forma, na concepção constitucional, há uma interação entre o homem e a natureza pela busca da "qualidade de vida" assentada necessariamente no "equilíbrio ecológico", e este implica, conseguintemente, o respeito a todas as formas de vida que compõem o complexo "sistema ecológico".

Na lógica antropocêntrica, a Constituição atribui como beneficiário do direito ao meio ambiente equilibrado as gerações presentes, mas já numa visão mitigada do antropocentrismo, inclui entre os beneficiários, também, as futuras gerações, numa evidenciada solidariedade intergeracional.

Mas, por outro lado, atribui inúmeros deveres aos implementadores da norma ambiental, que implicam a inclusão na proteção ambiental de beneficiários não humanos, portanto, adotando um saudável biocentrismo, que demonstra a visão holística e ecológica do texto constitucional.

É nesse sentido que o artigo 225 ordena: preservar e resguardar os "processos ecológicos essenciais" e prover o "manejo ecológico das espécies e ecossistemas" (art. 225, $\S 1^{\circ}$, inc. I); proibir qualquer utilização que comprometa a "integridade dos atributos" dos espaços territoriais especialmente protegidos $\left(\$ 1^{\circ}\right.$, inc. III); exigir "estudo prévio de impacto ambiental" para instalação de toda obra ou atividade potencialmente causadora de "significativa degradação" do meio ambiente $\left(\S 1^{\circ}\right.$, inc. IV); controlar a produção, a comercialização e o 
emprego de técnicas que importem "risco para a vida", "a qualidade de vida" e o "meio ambiente"; ( $\left(1^{\circ}\right.$, inc. V); promover a educação ambiental e a consciência pública para a "preservação do meio ambiente" ( $\S 1^{\circ}$, inc. VI); proteger a "fauna" e a "flora", vedadas as práticas que coloquem em risco "sua função ecológica" e provoque a "extinção de espécies" ou "submeta os animais à crueldade" ( $\S 1^{\circ}$, inc., VII). Além de dar especial proteção aos biomas da Floresta Amazônica, da Mata Atlântica, da Serra do Mar, do Pantanal Matogrossense e da Zona Costeira, na qualidade de patrimônios nacionais $\left(\S 4^{\circ}\right.$.); bem como tornando indisponíveis as terras devolutas necessárias a proteção dos "ecossistemas naturais" (§ $\left.5^{\circ}.\right)$.

Na luta pela conciliação do homem com a natureza, manter-se numa posição antropocêntrica não favorece qualquer avanço, pois o que se espera de todos os implementadores da juridicidade ambiental, e principalmente do Poder Judiciário, é que se reconheça que a natureza também possui um "valor intrínseco", pois a coragem de assumir tal postura inovadora no campo do jurídico significa dar-se um importante passo para a construção do novo paradigma da sustentabilidade ambiental (PADILHA, 2010, p. 166-169).

\section{O dever solidário de concretização da norma constitucional ambiental}

$\mathrm{Na}$ medida em que o compromisso constitucional com o meio ambiente é imposto a "todos", sendo dever do Estado e da coletividade a sua proteção, consoante o disposto no caput do artigo 225 da Carta Constitucional de 1988, a concretização real e efetiva de tal direito também cabe a "todos".

A vontade da Constituição determina a conduta dos poderes públicos e da sociedade; conforme ensina Konrad Hesse (1991, p.9), "a Constituição converter-se-á em força ativa se se fizerem presentes, na consciência geral [...] não só a vontade de poder, mas também a vontade de Constituição", portanto, a Constituição de um Estado Democrático de 
Direitos, que representa uma sociedade pluralista e aberta, deve ser interpretada e respeitada não apenas por um grupo de técnicos, mas por todos os intérpretes da Constituição.

Segundo Peter Haberle (1997), trata-se de uma sociedade aberta dos intérpretes da Constituição, o que exige a adoção de uma hermenêutica constitucional que inclua todos os segmentos da sociedade pluralista que representa. Portanto, a defesa do direito ao equilíbrio do meio ambiente trata de um poder-dever imposto a todos os intérpretes da Constituição, nele incluídos o "povo" que detém o pleno exercício da cidadania. E, segundo Haberle (1997, nota 16, p. 37):

Povo não é apenas um referencial quantitativo que se manifesta no dia da eleição e que, enquanto tal, confere legitimidade democrática ao processo de decisão. Povo é também um elemento pluralista para a interpretação que se faz presente de forma legitimadora no processo constitucional: como partido político, como opinião científica, como grupo de interesse, como cidadão.

O compromisso constitucional de defender e preservar o direito ao equilíbrio do meio ambiente impõe aos vários intérpretes da Constituição, desde o cidadão, os órgãos estatais, as organizações não governamentais, a opinião pública, o papel de dar-lhe efetividade, de extrair da Constituição a concretização de tal comando.

Entretanto, há de se reconhecer que a prática social pública e privada, no Brasil, é de devastação ambiental e não de preservação ambiental; nesse sentido, árduo é o caminho de conquista da concretização do novo paradigma constitucional ambiental, e da compreensão dos diversos atores sociais, dentre eles, a população, as empresas, os órgãos estatais, que necessitam adotar o comportamento da sustentabilidade ambiental em suas atividades cotidianas.

A efetividade da proposta constitucional para o meio ambiente depende, portanto, de uma sólida consciência social com relação ao direito ao meio ambiente saudável, reconhecendo o elevado valor do patrimônio natural e a necessidade de sua preservação para a sadia 
qualidade de vida das presentes e as futuras gerações (PADILHA, 2010, p. 170-171).

Segundo Canotilho (2007, p.5), na proteção do meio ambiente, exige-se um agir ativo e positivo do Estado e dos demais operadores públicos e privados, em quaisquer das formas jurídicas dessa atuação (normativa, planejadora, executiva, judicial).

Por outro lado, o acesso à Justiça do "direito ao equilíbrio do meio ambiente" exige a ampliação dos mecanismos de tutela judicial, possibilitando o acionamento do Poder Judiciário por meio da tutela processual coletiva, quando do descumprimento da proteção ambiental, cabendo, então, aos intérpretes judiciais, dar concretização ao novo paradigma da juridicidade ambiental, que, por sua vez, exigirá um novo papel do Poder Judiciário frente à sua atuação nas lides socioambientais.

\section{Os desafios do poder judiciário na concretização da norma constitucional ambiental}

A resolução dos conflitos que envolvem direitos meta ou transindividuais, tais como o meio ambiente, representa um grande desafio a ser enfrentado pelo direito enquanto fórmula social de resolução de conflitos. A evolução dos direitos, na sociedade, não pressupõe a extinção de quaisquer deles, mas a sua coexistência simultânea. O direito individual, o direito coletivo e o direito difuso convivem simultaneamente, na sociedade contemporânea, em graus e níveis jamais antevistos, e se conectam, se interligam e se chocam em complexos níveis de conflitos de interesses que clamam por solução rápida e eficaz.

E o Poder Judiciário, como poder estatal responsável pela aplicação do Direito, por sua vez, não efetuará resposta efetiva a tais conflitos, se pretender enquadrá-los numa visão meramente tecnicista do Direito, decidindo tais questões pela ótica do direito individual.

Os conflitos emergentes do confronto envolvendo direitos metaindividuais impõem um desafio ao Direito e seus operadores, o qual se inicia numa necessária e urgente tomada de consciência quanto 
ao atual impasse posto aos instrumentos jurídicos tradicionais e suas singelas soluções homogêneas e padronizadas, incapazes de albergar tão crescente complexidade de conflitos.

O papel do Direito no Estado Democrático compreende, antes, o de uma missão a cumprir perante a sociedade à qual ele se dirige e onde não basta que seja legitimamente imposto, mas implica que seja razoavelmente aceito. O Direito não se justifica a partir de conexões lógico-sistemáticas internas, porém deve ser instrumento de manutenção do Estado Democrático de Direito, refletindo um modelo racional, que concilie a legalidade com a razoabilidade, balizado pela ideia de Justiça.

O direito é um fenômeno decisional, implicando raciocínios que se caracterizam pela controvérsia, pelo desacordo e por escolhas, em que se acentua a necessidade de definição de critérios racionais que gerem a aceitabilidade das decisões a serem fundadas em opção de valores legitimados pela sociedade que o direito representa.

Assim, cabe ao Poder Judiciário, como missão, não só a resolução dos conflitos jurídicos mas também o convencimento social por meio da fundamentação da decisão judicial, alicerçada em critérios racionais, que permitam a justificação de escolha de valores, para a busca de sua legitimação. Na controvérsia do processo judicial, a decisão deve atentar, necessariamente, para a compreensão dos valores envolvidos, visando promover a decidibilidade do conflito (PADILHA, 2006, p. 1112).

Os conflitos que envolvem a questão socioambiental tornamse lides judiciais complexas, de altíssimo grau de conflituosidade, o que dificilmente possibilitará uma decisão com base em precedentes anteriores. Trata-se, indubitavelmente, de "casos difíceis", cuja decisão exige um sólida fundamentação.

O acesso à Justiça das lides ambientais impõe ao universo jurídico um momento especialmente desafiador e intrigante, impondo uma conflituosidade nova que não se resolve com mecanismos processuais tradicionais e institutos modelados em fórmulas individualistas, que 
não comportam a abrangência e a dinâmica dos atuais conflitos socioambientais.

Rompe-se a estrutura de um sistema pensado, para atuar junto aos conflitos dimensionados no interesse individual e cria-se o vácuo das intrigantes e gigantescas lides advindas dos direitos metaindividuais, dos direitos sem fronteiras, sem competência limitada pela jurisdição, sem titulares definidos, sem objeto estanque ou divisível, mas de altíssima carga de conflituosidade e urgente clamor de efetividade (PADILHA, 2006, p. 17-18).

As características da conflituosidade ambiental ocasionam lides judiciais complexas, ampliando, sobremaneira, a responsabilidade do Poder Judiciário e desafiando a sua capacidade, de seus instrumentos e de seus operadores, em regular, interpretar e apresentar soluções em um tal dimensionamento e dinâmica dos atuais conflitos socioambientais. Conforme bem preceituam Faria e Kuntz (2002, p. 62), a dimensão das lides hodiernas e seus riscos:

[...] tendem a não respeitar fronteiras, classes sociais e gerações futuras, colocando as [...] instituições jurídicas e judiciais do Estado-nação contemporâneo, do modo como foram concebidas e hoje se encontram estruturadas, com jurisdição territorialmente circunscrita, frente ao desafio quase intransponível de ter de se reformular radicalmente, para tentar criar alternativas institucionais, almejar oferecer respostas nacionais para questões de alcance global e conseguir neutralizar e/ou enfrentar esses problemas com um mínimo de efetividade.

Nesse contexto, o Poder Judiciário se vê frente à complexidade dos litígios que envolvem a juridicidade ambiental, para a qual, exigese uma nova postura e a apreensão do novo paradigma ético-jurídico da sustentabilidade, em busca de soluções jurídicas não previstas pela dogmática tradicional, mas de enfrentamento inevitável e não sujeito à adequação em fórmulas ultrapassadas e pré-determinadas. Porém, como aventado por Grinover (1998, p. 25), infelizmente: 
[...] nem todos os magistrados têm se demonstrado sensíveis aos desafios criados pelos novos tempos e nem todos têm sabido dar as necessárias respostas a conflitos diversos dos tradicionais, a serem solucionados por instrumentos processuais antes inexistentes, esboçados pela Constituição de 1988 e, em alguns casos, por leis ainda recentes. [...] Algum tempo haverá de passar, antes que a mentalidade do juiz brasileiro se adapte à nova ordem constitucional, que representou uma verdadeira ruptura em relação ao recente passado político e institucional do país.

Os conflitos judiciais que envolvem a litigiosidade ambiental exigem, para aventar uma possível via de resolução, quebra de paradigmas frente a dogmática tradicional, e coragem de enfrentamento de inovações e mudanças. O Direito não pode reduzir a dimensão de tais conflitos a uma visão meramente tecnicista, enfrentando tais questões pela ótica do direito individual. Enfim, as técnicas judiciárias aplicáveis a todo o arcabouço jurídico montado para tutela dos direitos individuais estão sofrendo o arrombamento de seus limites pela invasão dos conflitos de massa. Nesse contexto, o Poder Judiciário deve assumir o seu verdadeiro papel e tomar posição. O alargamento das vias de acesso ao Judiciário obriga o desenvolvimento de mecanismos de institucionalização dos conflitos de massa, buscando exigir do processo judicial a realização de uma vocação para o equilíbrio das forças sociais, servindo como efetivo instrumento de justiça social.

Cabe ao Poder Judiciário este novo e surpreendente desafio de enfrentamento das lides ambientais, que ampliaram extraordinariamente a complexidade do sistema jurídico, dificultando sobremaneira o trabalho dos operadores do direito, colocando-os "frente ao desafio de ter de neutralizar, por meio de regras gerais e abstratas e mecanismos processuais rígidos e hierarquizados, as pressões, as tensões e os conflitos decorrentes dos vínculos pluridimensionais entre os diversos âmbitos e níveis sociais" (FARIA; KUNTZ, 2002, p. 66-67).

Segundo Faria (2002), nessa situação-limite, advinda da emergência de uma conflituosidade nova, complexa e não padronizadas pelos paradigmas jurídicos vigentes, o Estado corre o risco de não 
mais conseguir regular a sociedade exclusivamente por meio de seus instrumentos jurídicos tradicionais e de suas soluções homogêneas ou padronizadoras, dada a superação, em termos burocráticos, organizacionais e administrativos de suas instituições judiciais, que se tem mostrado incapazes de decidir de modo coerente, uniforme e previsível as intricadas tramas e os densos entrelaçamentos promovidos pela "hiperjuridicização" ou "sobrejuridificação", tendo como resultado inevitável o aumento dos níveis de incerteza jurídica (FARIA, 2002, p. 78-79).

Urge, desta forma, uma necessária tomada de consciência por parte de todos os operadores do Direito, para o enfrentamento desta nova e complexa judicialidade decorrente das lides ambientais, que coloca em questionamento se está o jurista preparado para oferecer solução adequada a um tal dimensionamento de conflitos, pois, conforme Reale (1994, p. 95-97), conflitos e contradições são inevitáveis na experiência humana e, portanto, na experiência jurídica, mas cabe ao operador do direito superá-los de alguma forma.

\section{Ensino jurídico: necessidade de adequação aos novos horizontes da dogmática jurídica ambiental}

O ordenamento jurídico brasileiro fundou-se tradicionalmente no direito romano-germânico, apoiado numa construção normativa de direitos tradicionais, de conotação individual, sendo este o modelo da teoria geral do direito e da dogmática jurídica ministrada no Ensino do Direito nos cursos de graduação por todo o País, de evidente característica tradicionalista e apego ao conservadorismo, ensino que necessita se adaptar aos novos rumos da atual litigiosidade que está a exigir uma atualização dos meios e formas de atuação do Poder Judiciário.

A formação tradicional do bacharel em Direito centra-se na divisão tradicional, originada do Direito Romano, entre direito público e direito privado, com insuficiente abordagem aos atuais direitos de cidadania 
representados pelo novo campo dos direitos e interesses difusos, que implicam mecanismos de Democracia participativa e exigem uma maior sensibilidade social ou mesmo sociológica dos profissionais do Judiciário, para que tenham melhores condições de agir com a precisão esperada, nas questões que envolvam as lides de massa.

Como tão bem preleciona Grau (1998, p. 30), é preciso um novo "modo de pensar o direito", não apenas como norma, decisão, ordenamento e estrutura, mas sobretudo, o direito visto como "instância da realidade", mas alerta que, para tanto, é preciso "coragem" para enfrentar a mudanças de conceitos e estruturas tradicionais:

[...] uma enorme distância aparta o direito positivo porque apenas a ele, direito posto pelo Estado, temos dedicado atenção - dos estudos jurídicos que praticamos. É necessário transpormos essa distância, ainda que isso reclame coragem e ousadia. Coragem para reformularmos conceitos, critérios e princípios. Coragem para rompermos com esquemas estruturados sobre concepções antigas, no quadro de técnicas de ensino ultrapassadas - coragem de criarmos nossos próprios caminhos, o que reclama ousadia (GRAU, 1998, p. 30).

A temática ambiental provoca a necessidade de mudanças em conceitos e instrumentos jurídicos tradicionais, e o Ensino do Direito precisa se adequar à nova juridicidade ambiental. Há toda uma conflituosidade nova, complexa e extremamente abrangente por trás das lides socioambientais, não abrangidas pelos instrumentos de direito material e processual do ordenamento jurídico clássico.

Reitere-se que a visão sistêmica e holística de proteção jurídica do meio ambiente só foi constitucionalmente inaugurada pela Constituição Federal de 1988, pois as Constituições anteriores apenas se limitavam a tratar recursos ambientais com uma conotação civilística de uso e apropriação, e uma preocupação limitada à divisão de competências entre os entes da Federação para sua exploração, não albergando a proteção jurídica do equilíbrio ambiental. 
Desta forma, é a partir da Constituição Federal de 1988 que se estabelecem os alicerces deste novo e crescente ramo do Direito, o Direito Ambiental, que passa a se fortalecer com base no novo paradigma da constitucionalidade ambiental, com objeto e princípios próprios, conquistando sua autonomia como disciplina e ordenando uma releitura de todo o ordenamento jurídico infraconstitucional com base em novos parâmetros e fundamentos.

A partir da Constituição Federal de 1988, as leis anteriores com ela compatíveis e por ela albergadas, são reafirmadas e renovadas em um parâmetro constitucional novo, passando a compor, juntamente com a edição das leis infraconstitucionais posteriores a 1988, um sistema ordenado e complexo, que reescreve e reafirma a proteção ambiental sob as luzes do "equilíbrio do meio ambiente" na condição de um direito "essencial à sadia qualidade de vida" não só das presentes, mas também das futuras gerações.

O Direito Ambiental está em construção e luta pela sua afirmação, exigindo de todos os estudiosos do Direito um acurado empenho e dedicação para assimilação destes novos parâmetros da juridicidade ambiental que implicam, inclusive, conhecimentos multidisciplinares.

Trata-se de um direito novo, que exige uma abordagem diferenciada dos direitos individuais de cunho tradicional, sob o qual foi alicerçado todo o arcabouço do sistema jurídico nacional. Um direito novo que exige uma nova forma de interpretação e concretização, pois possui instrumentos de implementação complexos, princípios inovadores que lhe dão autonomia e identidade própria, uma rede de responsabilidades compartilhadas entre todos os atores sociais, extensa e farta produção legislativa, complexa divisão de competências entre os entes da Federação, grandiosa abrangência temática, envolvendo a proteção do meio ambiente natural e do artificial, além de abarcar conhecimentos multidisciplinares a exigir diálogo com outras ciências, tais como a ecologia e as ciências naturais.

Situa-se, ainda, dentre os direitos consagrados em meio ao processo de massificação da sociedade globalizada, de titularidade indefinida, que, segundo Bonavides (1999, p.522-523), são direitos 
"dotados de altíssimo teor de humanismo e universalidade" fundados na fraternidade, direitos que não se satisfazem na dimensão do público e do privado, mas exigem uma terceira via, a dos direitos metaindividuais.

Dentre os novos direitos, o direito ao meio ambiente, enquanto um direito de terceira dimensão, impõe quebra de paradigmas dentro da Ciência do Direito, pois o Direito Ambiental é o primeiro que nasce não para disciplinar apenas as relações humanas, dos homens entre si, mas para compor as relações do homem com a natureza, impondo, assim, uma quebra substancial do paradigma jurídico tradicional, passando a considerar uma especial parceria com a Ecologia e não apenas com a Antropologia, bem como ultrapassando consideravelmente qualquer abrangência limitada à visão meramente dogmática.

Tal potencialidade de efeitos que as normas de direito ambiental possuem confere-lhe um caráter multidisciplinar, perpassando todo o ordenamento jurídico, não se lhe impondo uma delimitação rígida e estática. É um direito em movimento, envolvendo a persecução de seu objetivo - o equilíbrio ambiental - os mais diversos campos da atividade humana.

Para Paulo Affonso Leite Machado (1996, p.71), o Direito Ambiental tende a penetrar todos os diferentes ramos clássicos do Direito, dado o seu caráter horizontal e seu poder de interação, com a finalidade de orientar todo o ordenamento num sentido ambientalista, assim se expondo:

Na medida em que o ambiente é a expressão de uma visão global das intenções e das relações dos seres vivos entre eles e com seu meio, não é surpreendente que o Direito do ambiente seja um Direito de caráter horizontal, que recubra os diferentes ramos clássicos do Direito (Direito Civil, Direito Administrativo, Direito Penal, Direito Internacional) e um Direito de interações, que se encontra disperso nas várias regulamentações. Mais do que um novo ramo do Direito com seu próprio corpo de regras, o Direito do ambiente tende a penetrar todos os sistemas jurídicos existentes para os orientar num sentido ambientalista. 
Corroborando no esclarecimento desse processo de interação do Direito Ambiental com os demais ramos do Direito, Paulo de Bessa Antunes (1990, p. 24) afirma que essa relação é uma relação transversal, explicando que,

as normas ambientais tendem a se incrustar em cada uma das demais normas jurídicas, obrigando a que se leve em conta a proteção ambiental em cada um dos demais 'ramos' do Direito", e que, na verdade, o Direito Ambiental "penetra em todos os demais ramos da Ciência Jurídica.

Ademais, o Direito Ambiental possui uma extensa abrangência, atingindo os mais diversos aspectos do meio ambiente, que é, por si só, uma temática multidisciplinar. Desta forma, a juridicidade ambiental abrange não só meio ambiente natural, mas também o meio ambiente artificial, razão pela qual a legislação ambiental é extremamente extensa, abrangendo significativas áreas de incidência, desde o meio ambiente natural ou físico até as variadas expressões do meio ambiente artificial, como o referente ao direito urbanístico, o do meio ambiente cultural, e o do meio ambiente do trabalho, uma vez que não se limita às questões referidas apenas aos elementos bióticos e abióticos do meio ambiente, mas a todas as suas interações com o ser humano no seu contexto social, econômico, geográfico etc.

Tais características diferenciadas do Direito Ambiental, sua abrangência e especial complexidade, bem como os desafios de sua finalidade - o paradigma da sustentabilidade ambiental - impõem uma nova postura aos implementadores da legislação ambiental, para a qual, entretanto, não foram preparados pelo modelo dogmático tradicionalista do ensino jurídico praticado pelos Cursos de direito no Brasil.

Registre-se que as diretrizes curriculares do Ensino Jurídico nos Cursos de graduação em Direito no Brasil foram submetidas a um avanço com relação ao ensino meramente positivista e dogmático que predominou desde a sua criação no País ${ }^{4}$, e isto se deu somente a partir

4 O Curso de Direito de São Paulo foi instalado no Convento do Largo de São Francisco em $1^{\circ}$ de março de 1828, e em 15 de maio do mesmo ano deu-se a criação do Curso de Direito de Olinda, no Mosteiro de São Bento, que posteriormente, em 1854 foi transferido para Recife. 
da edição da Portaria do MEC n. 1886, de 30 de dezembro de 19945, que determinou um currículo mínimo dividido em disciplinas obrigatórias e profissionalizantes. Em um contexto de busca de qualidade frente à preocupante proliferação de Cursos de Direito pelo País, foram introduzidas disciplinas propedêuticas responsáveis por uma formação mais humanística dos bacharéis, tais como: Sociologia Geral e Jurídica, Introdução à Ciência do Direito, Filosofia Geral e Jurídica, Ciência Política e Teoria Geral do Estado, além de Ética Geral e Profissional. Mas, com relação às disciplinas profissionalizantes, responsáveis pela formação técnica do bacharel, incluem-se apenas: Direito Constitucional, Administrativo, Civil, Comercial, Penal, Direito do Trabalho, Processual Civil e Penal, Direito Internacional e Direito Tributário. ${ }^{6} \mathrm{O}$ espaço para o "novos direitos", dentre eles, o Direito Ambiental, não foram diretamente contempladas, relegando-se ao critério discricionário de cada Curso, de acordo com suas peculiaridades. ${ }^{7}$

Desta forma, mesmo após a edição da Portaria MEC n. 1886/94, que representou um grande avanço na qualidade do ensino de Direito no Brasil, e mesmo já transcorridos seis anos da promulgação da CF/88, não houve a inclusão obrigatória do ensino do Direito Ambiental nos Cursos Jurídicos, que ficou legado à decisão do projeto pedagógico de cada curso, por meio de disciplinas optativas ou complementares, atrasando de forma preocupante a qualificação adequada dos futuros juristas com relação ao paradigma da juridicidade ambiental.

5 A Portaria MEC 1886/1994 foi editada para adequar os Cursos Jurídicos a Constituição Federal de 1988, mas antes da Lei de Diretrizes e Bases (Lei 9.394/1996)

$6 \quad$ "Art. $6^{\circ} \mathrm{O}$ conteúdo mínimo do curso jurídico, além do estágio, compreenderá as seguintes matérias, que podem estar contidas em uma ou mais disciplinas do currículo pleno de cada curso. I - Fundamentais Introdução ao Direito, Filosofia geral e jurídica, ética geral e profissional), Sociologia (geral e jurídica), Economia e Ciência Política (com Teoria do Estado), II - Profissionalizante Direito Constitucional, Direito Civil, Direito Administrativo Direito Tributário. Direito Penal. Direito Processual Civil. Direito Penal. Direito do Trabalho, Direito Comercial e Direito Internacional."

7 Conforme art. $6^{\circ}$., parágrafo único da Portaria MEC n. 1886/94: "As demais matérias e novos direitos serão incluídos nas disciplinas em que se desdobrar o currículo pleno de cada curso, de acordo com suas peculiaridades e com observância de interdisciplinaridade." 
Tais diretrizes curriculares não foram consideravelmente alteradas pela atual Resolução do MEC n. 09, de 29 de setembro de 2004, que passa a tratar das Diretrizes Curriculares do Curso de Graduação em Direito, e que promove um avanço ao dar um maior espaço de destaque ao Projeto Pedagógico, impondo, de forma inovadora em seu artigo $3^{\circ}$., a necessidade de:

[...] assegurar ao perfil do graduando, sólida formação geral, humanística e axiológica, domínio de conceitos e da terminologia jurídica, adequada argumentação, interpretação e valorização dos fenômenos jurídicos e sociais, aliada a uma postura reflexiva e de visão crítica que fomente a capacidade e a aptidão para a aprendizagem autônoma e dinâmica, indispensável ao exercício da Ciência do Direito, da prestação da justiça e do desenvolvimento de cidadania.

De acordo com a atual Resolução os cursos de Direito, deverão contemplar, em seu Projeto Pedagógico e em sua Organização Curricular, conteúdos e atividades que atendam eixos interligados de formação, quais seja, o eixo de formação fundamental, o eixo de formação profissional e o eixo de Formação Prática. ${ }^{9}$

8 CNE. Resolução CNE/CES 9/2004. Diário Oficial da União, Brasília, $1^{\circ}$ de outubro de 2004, Seção 1, p. 17.

9 De acordo com a Resolução do MEC n. 09, de 29 de setembro de 2004, "art. 50: I - Eixo de Formação Fundamental, tem por objetivo integrar o estudante no campo, estabelecendo as relações do Direito com outras áreas do saber, abrangendo, dentre outros, estudos que envolvam conteúdos essenciais sobre Antropologia, Ciência Política, Economia, Ética, Filosofia, História, Psicologia e Sociologia; II - Eixo de Formação Profissional, abrangendo, além do enfoque dogmático, o conhecimento e a aplicação, observadas as peculiaridades dos diversos ramos do Direito, de qualquer natureza, estudados sistematicamente e contextualizados segundo a evolução da Ciência do Direito e sua aplicação às mudanças sociais, econômicas, políticas e culturais do Brasil e suas relações internacionais, incluindo-se necessariamente, dentre outros condizentes com o projeto pedagógico, conteúdos essenciais sobre Direito Constitucional, Direito Administrativo, Direito Tributário, Direito Penal, Direito Civil, Direito Empresarial, Direito do Trabalho, Direito Internacional e Direito Processual; e III - Eixo de Formação Prática, objetiva a integração entre a prática e os conteúdos teóricos desenvolvidos nos demais Eixos, especialmente nas atividades relacionadas com o Estágio Curricular Supervisionado, Trabalho de Curso e Atividades Complementares."(Grifou-se). 
Verifica-se, desta forma, que dentre os conteúdos a serem ministrados na formação dos futuros bacharéis em Direito, acrescentouse, no Eixo Fundamental, antropologia, psicologia e história, mantendo sem muitas alterações a formação profissional.

$\mathrm{E}$, mesmo com o intuito de atualizar o ensino jurídico às novas demandas sociais, econômicas, políticas e culturais do Brasil, a atual Resolução n. 9, lamentavelmente, não atentou para a necessidade da inclusão do ensino do Direito Ambiental, disciplina jurídica que representa o novo paradigma constitucional ambiental, e que, mesmo depois de transcorridos mais de vinte anos da promulgação da CF/88, permanece sem um espaço adequado ou sequer garantido no conteúdo das Diretrizes Curriculares que fazem parte da preparação dos futuros bacharéis em Direito.

A inclusão não obrigatória do ensino do Direito Ambiental nos cursos jurídicos, bem como de conhecimentos que lhe são correlatos, tais como a Teoria Geral dos Direitos Difusos e Coletivos e Tutela Processual Coletiva, relega a um patamar meramente secundário seu conhecimento e seu estudo pelos futuros bacharéis de Direito, pois a inclusão de tais disciplinas, em seu projeto pedagógico e nas diretrizes curriculares, depende da decisão de cada curso jurídico, e da escolha particular dos alunos, o que ocasiona a mera possibilidade de inclusão de tais temáticas, ou mesmo sua inclusão tardia e insuficiente e, até mesmo, a total ausência do ensino de tão relevantes conhecimentos. Desta forma, a possibilidade de que a disciplina de Direito Ambiental seja ofertada no Curso de Direito de forma meramente suplementar, sujeita à livre escolha do bacharel, como um assunto subsidiário, continua a relegar o direito ao equilíbrio do meio ambiente a um plano meramente secundário ou de menor relevância no Ensino Jurídico.

Entretanto, a questão ambiental ocupa um espaço considerável em termos de complexidade nos atuais casos difíceis que estão a exigir a atuação do Poder Judiciário, por meio de demandas socioambientais que solicitam a implementação adequada da normatividade ambiental, que, por sua vez, está diretamente ligada à concretização do princípio 
da preservação da vida, em todas as suas formas. Assim, é de suma importância que o ensino do Direito Ambiental e das temáticas correlatas ocupem o espaço de relevância na formação dos juristas, futuros implementadores do paradigma da sustentabilidade ambiental e do novo modelo ético-jurídico e político econômico imposto constitucionalmente.

O conhecimento adequado da normatividade ambiental é de crucial importância para que o Poder Judiciário bem exerça seu papel na busca pela efetividade da promessa constitucional de proteção ao equilíbrio do meio ambiente. Os implementadores judiciais da normatividade ambiental precisam ter consciência de seu papel, sem o qual não lograrão dar eficácia social ao compromisso constitucional com a qualidade de vida. Impor a concretização do equilíbrio do meio ambiente pela via judicial é, hodiernamente, um dos maiores desafios do Poder Judiciário, reiterando-se que tais conflitos colocam em risco a sadia qualidade de vida do homem, intrinsecamente atada ao equilíbrio do meio ambiente; portanto, defender a efetividade das normas ambientais importa defender a efetividade de direitos humanos fundamentais.

Parece-nos preocupante que os Cursos de Direito no Brasil não incluam adequadamente, e o quanto antes, o estudo do Direito Ambiental em suas Diretrizes Curriculares, pois não estarão propiciando aos futuros profissionais o estudo dos valores constitucionais ambientais, que impõem a reformulação de conceitos, institutos e princípios, exigindo todo um novo arcabouço de conhecimentos, cuja atualização é imprescindível para que o profissional do Direito saiba como atuar eficientemente diante das demandas socioambientais, representando adequadamente o papel que lhes cabe nesta luta pela conquista da sadia qualidade de vida.

Os desafios postos à proteção jurídica ambiental exigem uma nova prática do ensino jurídico tradicional, que compreenda a superação da concepção individualista e patrimonialista que acentua apenas o cunho de dominialidade com relação aos recursos naturais, modelo de juridicidade ambiental superado pelo paradigma constitucional ambiental albergado pela Constituição Federal de 1988. 
O Direito Ambiental possui, assim, um papel essencial no ensino jurídico, pois a eficácia de suas normas é primordial na imposição de limites éticos e jurídicos, na atuação e interferência humana no meio ambiente, seja ele natural ou artificial, e na contribuição para reformulação de valores da sociedade brasileira para com o meio ambiente.

Dentre as características do Direito Ambiental, que acentuam a necessidade de novos mecanismos para sua implementação, há que se considerar que se trata de um direito de natureza difusa, um direito transindividual que é tutelado judicialmente por meio da tutela processual coletiva, um micro sistema processual que se inicia com a Lei da Ação Popular e principalmente pela via da Ação Civil Pública, e se fortalece com a Constituição Federal de 1988 e se completa com o Código de Defesa do Consumidor. A tutela processual coletiva inova e modifica consideravelmente a tutela processual tradicional de natureza singular, desde o objeto das ações coletivas referido aos direitos difusos, coletivos e individuais homogêneos, até a legitimidade ativa definida entre co-legitimados adequados, como o Ministério Público, a Defensoria Pública, as Associações Civis e os órgãos públicos da Administração Direta e Indireta. Inova, ainda, a forma de execução designando um Fundo de direitos difusos para onde se destina o resultado monetário da ação, além de alterar consideravelmente os próprios efeitos da coisa julgada que é mitigada para atender o resultado do processo.

É essencial que as Diretrizes Curriculares dos Cursos Jurídicos se atualizem para superar o ensino arraigado na tradição jurídica do individualismo, de um sistema referido apenas a um universo do "público" e do "privado", dos direitos referidos apenas ao indivíduo e ao Estado, e passem a considerar com toda sua complexidade os direitos metaindividuais, dentre os quais, o meio ambiente, enquanto um direito sem titular definido, de objeto indivisível e sem fronteiras determinadas, situado no cerne da conflituosidade global.

Destaque-se, neste contexto, a relevante preocupação de José Eduardo Faria (2008, p. 114-115) com relação à continuidade do paradigma normativista tradicional nos cursos jurídicos: 
Diante dessas indagações e das rupturas epistemológicas a ela inerentes, o problema é saber se podemos continuar agindo e pensando com base em padrões, categorias, conceitos $\mathrm{e}$ instrumentos analíticos que privilegiam o formalismo jurídico - em suma, com base nos modelos teóricos do paradigma normativista até hoje prevalecente nas faculdades de direito mais tradicionais do País, baseados no levantamento sistemático da legislação, da jurisprudência predominante nos tribunais [...]. Trata-se de uma formação dogmática, de viés quase exclusivamente forense, que chega a ser constrangedoramente singela quando contrastada com o grau de complexidade do universo normativo globalizado e dos níveis de formação, qualificação e especialização hoje exigidos no mercado de trabalho dos operadores de direito.

\section{Conclusão}

Ao adotar o direito ao meio ambiente equilibrado na qualidade de um direito fundamental, a Constituição Federal de 1988 elevou o valor da preservação ambiental ao nível constitucional, dando-lhe relevante importância e destaque, e estabelecendo um novo paradigma constitucional de juridicidade ambiental.

E, embora o dever de implementação do paradigma da sustentabilidade ambiental, para garantia da sadia qualidade de vida de todos, seja atribuído de forma solidária e compartilhada entre todos os atores sociais, tanto no âmbito público ou privado, destaca-se a importância do relevante papel do Poder Judiciário na concretização do compromisso ambiental assumido constitucionalmente, principalmente diante de uma realidade histórica e cultural de desrespeito e exploração desmedida dos recursos naturais no País, cabendo-lhe, portanto, a decisão final de inúmeras e complexas lides socioambientais.

Cabe aos implementadores do compromisso constitucional ambiental um papel árduo e essencial, atuando nas lides ambientais em prol da concretização do novo paradigma ético-jurídico da 
sustentabilidade ambiental, impondo, por suas decisões, respeito e consideração, de forma prioritária, aos riscos e perigos à sadia qualidade de vida, dando efetividade ao Princípio da Prevenção e da Precaução, que estabelecem os níveis de sustentabilidade de exploração e utilização dos recursos naturais, e a defesa e proteção da qualidade de vida humana, sem deixar de considerar o respeito devido ao meio ambiente, também em si mesmo considerado.

Sem consciência do seu papel, os implementadores da proteção jurídica do meio ambiente não lograrão dar efetividade a esse arcabouço da juridicidade ambiental, que, antes de qualquer outro parâmetro, deve observar na sua interpretação e aplicação - o princípio da PRESERVAÇÃO DA VIDA, em todas as suas formas. Tais atores da implementação da normatividade ambiental devem ter claro que concretizar juridicamente o equilíbrio do meio ambiente é hodiernamente uma de suas mais importantes responsabilidades, pois o homem e o meio ambiente fazem parte da mesma teia de vida, portanto, a efetividade das normas ambientais implicam a efetividade de direitos humanos fundamentais.

Porsuavez, oensino praticadonos Cursos de Direito devem propiciar aos futuros profissionais o estudo dos valores constitucionais ambientais e do novo paradigma ético-jurídico imposto pelo reconhecimento do direito ao meio ambiente ecologicamente equilibrado, enquanto um direito de terceira dimensão, que impõe a reformulação de conceitos, institutos e princípios, e a releitura transversal do ordenamento jurídico, inclusive por meio de conhecimentos e diálogos multidisciplinares.

Desta forma, as Diretrizes Curriculares devem introduzir, de forma eficiente e obrigatória, o ensino do Direito Ambiental, da Tutela Processual Coletiva e da Teoria Geral dos Direitos Difusos e Coletivos, para que possam preparar o futuro profissional de Direito de forma adequada e condizente com a atual complexidade das lides socioambientais, tornando-os aptos a desempenhar condizentemente seu papel no processo de adaptação e reestruturação do modelo socioeconômico atual com o necessário equilíbrio do meio ambiente, tendo em vista a sadia qualidade de vida. 
O ensino atualizado do Direito Ambiental nos Cursos de Graduação em Direito no Brasil, abordando toda sua dimensão e considerando sua característica multidisciplinar e transversal que afeta todas as demais áreas do saber jurídico, tem reflexo direto na possibilidade de atuação eficiente e competente do Poder Judiciário, no trato com as diferenciadas lides socioambientais, que se configuram em casos judiciais difíceis, de alto grau de complexidade e geradoras de resultados de ampla abrangência em variados setores da sociedade, quer culturais, ambientais, políticos e econômicos.

Os desafios postos à proteção jurídica do meio ambiente, enquanto um valor da sociedade brasileira, essencial à sadia qualidade de vida das presentes e futuras gerações, passa, também, dentre tantas outras complexas variáveis, pela imposição de uma nova prática do ensino jurídico tradicional, que construa de forma adequada o conhecimento dos futuros implementadores da juridicidade ambiental, e os torne capazes de atuar com serenidade e eficiência nas complexas lides socioambientais, utilizando com habilidade os instrumentos jurídicos aptos a propiciar a adequada e necessária ponderação que deve ser aplicada no raciocínio jurídico diante do conflito entre desenvolvimento e preservação do meio ambiente, valores altamente essenciais à sadia qualidade de vida, e rotineiramente em colisão na realidade social.

Para enfrentar o tamanho de tal desafio, cabe também ao ensino jurídico superar a concepção patrimonialista de cunho material do ordenamento jurídico tradicional, adaptando-se e atualizandose na apreensão e compreensão do novo paradigma ético-jurídico e econômico-social imposto pela juridicidade constitucional ambiental e de seus instrumentos.

O Direito Ambiental possui, assim, um papel essencial no ensino jurídico, não podendo ficar relegado a um papel secundário e opcional, pois a conquista da efetividade de suas normas é primordial diante do desafio de imposição de limites éticos e jurídicos na atuação e interferência humana no meio ambiente, seja ele natural ou artificial, e na conquista da afirmação dos valores essenciais para a qualidade 
de vida da sociedade brasileira, também garantida por uma atuação eficiente, inovadora e corajosa do Poder Judiciário, no cumprimento de sua missão na resolução dos conflitos socioambientais, na defesa das normas constitucionais ambientais e na busca de uma Justiça Ambiental.

\section{Referências}

ANTUNES, Paulo de Bessa. Curso de direito ambiental. Rio de Janeiro: Renovar, 1990.

BARROSO, Luís Roberto. Fundamentos teóricos e filosóficos do novo direito constitucional brasileiro. Revista da Academia Brasileira de Direito Constitucional, Curitiba, v. 1, n. 1, p. 17-59, 2001.

BONAVIDES, Paulo. Curso de direito constitucional. 8. ed. São Paulo: Malheiros, 1999.

CANOTILHO, J. J. Gomes. Curso de direito constitucional. 8. ed. São Paulo: Malheiros, 1999.

. Direito público do ambiente. Coimbra: Faculdade de Direito de Coimbra, 1995.

; LEITE, José Rubens Morato (Org.). Direito constitucional ambiental brasileiro. São Paulo: Saraiva, 2007.

CAPPELLETTI, Mauro. Formações sociais e interesses coletivos diante da justiça civil. Revista de Processo, São Paulo, n. 5, p. 45-56, 1977.

FARIA, José Eduardo; KUNTZ, Rolf. Qual o futuro dos direitos? Estado, mercado e justiça na reestruturação capitalista. São Paulo: Max Limonad, 2002.

FREITAS, Vladimir Passos. A constituição federal e a efetividade das normas ambientais. 3. ed. São Paulo: Revista dos Tribunais, 2005.

GRAU, Eros Roberto. O direito posto e o direito pressuposto. 2. ed. São Paulo: Malheiros, 1998. 
GRINOVER, Ada Pellegrini. A crise do poder judiciário. In: . 0 processo em evolução. 2. ed. Rio de Janeiro: Forense Universitária, 1998. p. 56-68.

HABERLE, Peter. Hermenêutica constitucional: a sociedade aberta dos intérpretes da constituição: contribuição para a interpretação pluralista e procedimental da constituição. Porto Alegre: Fabris, 1997.

HABERMAS, Jürgen. Direito e democracia: entre facticidade e validade. Rio de Janeiro: Tempo Brasileiro, 1997.

HESSE, Konrad. A força normativa da constituição. Tradução de Gilmar Ferreira Mendes. Porto Alegre: Fabris, 1991.

LEFF, Enrique. Epistemologia ambiental. Tradução de Sandra Valenzuela. São Paulo: Cortez, 2001.

MACHADO, Paulo Affonso Leme. Direito ambiental brasileiro. 6. ed. São Paulo: Malheiros, 1996.

. Direito ambiental brasileiro. 15. ed. São Paulo: Malheiros, 2007.

MILARÉ, Edis. Direito do ambiente: doutrina, jurisprudência, glossário. 5. ed. São Paulo: Revista dos Tribunais, 2007.

MUKAI, Toshio. Direito ambiental sistematizado. 2. ed. São Paulo: Forense Universitária, 1991.

PADILHA, Norma Sueli. Colisão de direitos metaindividuais e a decisão judicial. Porto Alegre: Fabris, 2006.

. Do meio ambiente do trabalho equilibrado. São Paulo: Ltr, 2002.

\section{Fundamentos constitucionais do direito ambiental} Brasileiro. Rio de Janeiro: Campus/Elsevier, 2010.

REALE, Miguel. Fontes e modelos do direito: para um novo paradigma hermenêutico. São Paulo: Saraiva, 1994. 
. O judiciário a serviço da sociedade. Revista da Ajuris, Porto Alegre, n. 21, p. 62, p. 78-86, nov. 1994.

1998.

. Lições preliminares de direito. 24. ed. São Paulo: Saraiva,

RUIZ, Urbano. A questão do judiciário e da justiça no Brasil. In: RIBEIRO, José Ernanne et al. (Org.). Ética, justiça e direito: reflexões sobre a reforma do poder judiciário. Rio de Janeiro: Vozes, 1996. p. 67-78.

SARLET, Ingo Wolfgang. A eficácia dos direitos fundamentais. 5. ed. Porto Alegre: Livraria do Advogado, 2005.

SILVA, José Afonso da. Curso de direito constitucional positivo. 9. ed. São Paulo: Malheiros, 1994.

2007.

. Direito ambiental constitucional. 6. ed. São Paulo: Malheiros,

SOARES, Guido Fernando Silva. Direito internacional do meio ambiente: emergência, obrigações e responsabilidades. 2. ed. São Paulo: Atlas, 2003.

Recebido em: 31/05/2011

Avaliado em: 26/08/2011

Aprovado para publicação em: 27/10/2011 